\title{
PROINFÂNCIA: OFERTA DE UMA EDUCAÇÃO COM QUALIDADE PARA A CRIANÇA CIDADÃ?
}

Nelcir Francisca da Silva ${ }^{1}$ Ilma Vieira do Nascimento ${ }^{2}$

\section{RESUMO}

O interesse pela educação de crianças pequenas não é recente, havendo desde o século XIX manifestações sobre essa questão expressas em torno do mobiliário escolar e de outros pontos a estes associados relativos aos espaços escolares, como as creches e os jardins de infância. Este artigo trata do Programa Nacional de Reestruturação e Aquisição de Equipamentos para a Rede Escolar Pública de Educação Infantil (Proinfância), criado no ano de 2007 no contexto de políticas focadas na melhoria da qualidade da educação básica e no reconhecimento da criança como um ser de direitos. Situa o Programa nos dois eixos de atuação - a construção de creches e pré-escolas e a aquisição de mobiliários e equipamentos para o funcionamento da rede física da educação infantil, em uma comunidade do município maranhense de São José de Ribamar. Este estudo revela que creches construídas sob o modelo Proinfância não constituem, por si só, fatores suficientes para conferir um padrão de qualidade à educação de crianças; soma-se a este relevante aspecto infraestrutural, a necessária formação inicial e continuada dos (as) professores (as) envolvidos no processo educativo.

Palavras-chave: Educação Infantil. Qualidade da Educação Básica. Proinfância.

\footnotetext{
${ }^{1}$ Mestra em Educação do Programa de Pós-Graduação em Educação da Universidade Federal do Maranhão. Professora - Funcionária pública concursada/Sistema Municipal de Educação de São José de Ribamar/MA. E-mail: nelcirfr@gmail.com

2 Doutora em Educação pela Universidade de São Paulo. Professora do Programa de PósGraduação em Educação da Universidade Federal do Maranhão -PPGE/UFMA. E-mail: ilmavieira13@gmail.com
} 


\section{PROINFANCY: PROVIDING QUALITY EDUCATION FOR THE CHILD CITIZEN?}

\section{ABSTRACT}

The interest in the education of young children is not recent, and since the 19th century there have been manifestations on this issue expressed around school furniture and other related points related to school spaces, such as day care centers and kindergartens. This article deals with the National Program for the Restructuring and Acquisition of Equipment for the Public School Network for Early Childhood Education (Proinfancy), created in 2007 in the context of policies focused on improving the quality of basic education and recognizing the child as a being. rights. The Program is located in two areas of activity - the construction of daycare centers and preschools and the purchase of furniture and equipment for the operation of the physical network of early childhood education, in a community in the municipality of São José de Ribamar, Maranhão. This study reveals that daycare centers built under the Proinfância model are not, in themselves, sufficient factors to provide a quality standard for children's education; in addition to this relevant infrastructure aspect, the necessary initial and continuing training of teachers involved in the educational process.

Keywords: Child education. Quality of Basic Education. Prochildhood.

\section{PRO-NIÑEZ: ¿BRINDAR EDUCACIÓN DE CALIDAD AL NIÑO CIUDADANO?}

\section{RESUMEN}

El interés por la educación de los niños pequeños no es reciente, y desde el siglo XIX se han producido manifestaciones sobre este tema expresadas en torno al mobiliario escolar y otros puntos afines relacionados con los espacios escolares, como guarderías y jardines de infancia. Este artículo trata del Programa Nacional de 
Reestructuración y Adquisición de Equipamiento para la Red de Escuelas Públicas de Educación Infantil (Proinfancy), creado en 2007 en el contexto de políticas enfocadas a mejorar la calidad de la educación básica y al reconocimiento del niño como ser. derechos. El Programa se ubica en dos áreas de actividad: la construcción de guarderías y jardines de infancia y la compra de mobiliario y equipamiento para el funcionamiento de la red física de educación infantil, en una comunidad del municipio de São José de Ribamar, Maranhão. Este estudio revela que las guarderías construidas bajo el modelo Proinfância no son, en sí mismas, factores suficientes para brindar un estándar de calidad en la educación de los niños; Además de este relevante aspecto de infraestructura, la necesaria formación inicial y continua de los docentes involucrados en el proceso educativo.

Palabras clave: Educación Infantil. Calidad de la educación básica. Pro-niñez.

\section{INTRODUÇÃO}

Este artigo tem origem em uma pesquisa que trata da formação de professores que atuam na educação infantil e as relações entre o processo de formação desses profissionais com as condições necessárias para a realização do trabalho docente em creches e pré-escolas. $\mathrm{O}$ artigo, ora apresentado, constitui um recorte dessa pesquisa em que se enfatiza o Programa Nacional de Reestruturação e Aquisição de Equipamentos para a Rede Escolar Pública de Educação Infantil (PROINFANCIA), que foca a estrutura física e pedagógica de creches padronizadas como um dos requisitos primordiais a conferir qualidade à educação de crianças de 0 a 5 anos de idade.

Tal requisito, afeto a aspectos infraestruturais nos quais se inclui a aquisição de equipamentos e mobiliário, é entendido no contexto de avanços políticos que repercutem no campo da educação pelo reconhecimento da criança como um ser de direitos assegurados em legislações pertinentes. São direitos universais que 
no plano conceptual se dirigem a todas as crianças, independente de condições econômicas, sociais, culturais, entre outras.

O Proinfância veio ao encontro de reivindicações de pesquisadores e defensores dos direitos das crianças por uma educação infantil com qualidade e equidade como indicam as diretrizes e parâmetros para a educação escolar de crianças em creches e pré-escolas. Soma-se a isso, o reconhecimento de que a criança, embora seja portadora de características comuns "[...] em relação aos ritmos de crescimento e necessidades fundamentais, como afeto, proteção alimentação, higiene, há mais características que as diferenciam entre si [...]." (SOUZA, 2011, p. 10).

Assim, em tal perspectiva embora envolvidas por características comuns, as crianças estão sujeitas a condicionamentos externos a elas afetando-as, sobretudo em tempos atuais que impõem às mães o exercício de atividades fora do ambiente doméstico, o que incide sobre o cuidar e educar a criança pequena. Nesse sentido, a oferta de espaços adequados que venham suprir a "ausência" da ambiência familiar torna-se imperiosa e é em tal perspectiva que o Proinfância se configura, mormente em municípios que requerem ações concretas e urgentes dos poderes públicos em atendimento às demandas para a construção de creches e préescolas.

A pesquisa em referência, realizada em um município pertencente à região metropolitana de São Luís/MA, teve como campo empírico, uma creche municipal construída no padrão Proinfância, situada em um conjunto habitacional para pessoas de baixa renda que reivindicavam a construção de espaços educacionais adequados ao atendimento de crianças de 0 a 5 anos.

EDUCAÇÃO INFANTIL: avanços na construção das ideias e práticas para cuidar e educar crianças pequenas

A educação infantil é a fase da escolaridade que mais tem crescido no Brasil nos últimos anos, verificando-se desde os anos de 1970, um impulso para o atendimento da criança de 0 a 6 anos no âmbito das políticas governamentais. A partir dos anos de 1980 
acentuam-se os debates sobre educação infantil demarcados, de um lado, pelo objetivo traçado pelo MEC de expandir o atendimento às crianças em fase pré-escolar, mas a baixo custo; de outro, por reações advindas de movimentos sociais, universidades, redes de ensino entre outros, em defesa da articulação das políticas orientadas para a educação infantil com as políticas sociais.

Desde o século passado já se desenvolvem debates e discussões nas mais variadas esferas da sociedade sobre a educação escolar infantil que ganham dimensões positivas na direção do direito das crianças à instituição escolar; a década de 1980, desse século, assinala o propósito de reconfigurar o sentido da Educação Infantil à luz das transformações em curso na sociedade brasileira contemporânea.

No tocante à reconfiguração da Educação Infantil Pública, a concretização desse direito tem sido desafiadora para pesquisadores e profissionais da educação, do mesmo modo para os movimentos sociais em defesa de mecanismos equitativos, havendo a participação conjunta de médicos, juristas, educadores, políticos nessa importante conquista. Esse estímulo advém daquela década, então envolvida pelo movimento de redemocratização do país, com repercussões sobre a obrigatoriedade da Educação Infantil com qualidade, no âmbito das políticas educacionais, como relatam Leite Filho e Nunes, (2013, p. 6):

Registra-se como da maior significação nesse processo de conquista da educação infantil no Brasil o Movimento Nacional Criança e Constituinte, organizado em 1986 a fim de elaborar uma proposta para a área da criança. A Comissão Nacional Criança e Constituinte que foi criada por portaria do Ministério da Educação (MEC) com representantes do Ministério da Educação, da Saúde, da Cultura, do Planejamento, do Trabalho, da Assistência Social, e da Justiça e pelas seguintes organizações: OAB, Sociedade Brasileira de Pediatria, Federação Nacional de Jornalismo, Organização Mundial para a Educação Pré-Escolar (Omep) Brasil, Fundo das Nações Unidas para Infância (Unicef), Conferência Nacional dos Bispos 
do Brasil (CNBB)/ Pastoral da Criança, Conselho Nacional dos Direitos da Mulher, Frente Nacional dos Direitos da Criança e Movimento Nacional Meninos e Meninas de Rua. Nos estados foram criadas comissões com uma composição semelhante. No total, mais de 600 organizações governamentais e não governamentais estiveram envolvidas no movimento, durante dois anos.

De acordo com os autores citados, o resultado desse movimento organizado em favor da educação infantil ganhou força e tornou-se oficialmente um direito para as crianças brasileiras e estrangeiras, independentemente do gênero, cor, etnia, classe social, credo religioso ou político, com ou sem deficiência. Como destacam, a legislação criada a partir de então que trata do direito das crianças brasileiras à educação decorre, em grande parte, de pressões de movimentos organizados da sociedade, como estamos a destacar.

No rol das discussões toma corpo a imperiosa necessidade de alocar investimentos na educação escolar como um todo, assim como investir na formação dos docentes da Educação Básica.

A Constituição Federal de 1988 (BRASIL, 1998) é um marco na definição de uma nova visão de seguridade social, na medida em que os cidadãos, sem exceção, são reconhecidos como portadores do direito de serem assistidos em suas necessidades básicas pelo Estado (SOUSA; BARBOSA, 2012).

Quanto ao específico da Educação Infantil há o reconhecimento de avanços e estes são visíveis nas políticas públicas e programas oficiais nas esferas federais e municipais, ressaltando-se a Lei de Diretrizes e Bases da Educação Nacional - LDBN (Lei n. 9.394/1996) que insere a Educação Infantil como etapa inicial da Educação Básica e a define como um direito da criança de 0 a 5 anos e um dever do Estado em atendê-la em creches e pré-escolas. (BRASIL, 1996).

A década de 1990 se configura como marco temporal de reformas no âmbito do Estado com incidências vigorosas nas políticas educacionais, entre as quais as direcionadas para a infância. O Estatuto da Criança e do Adolescente - ECA (Lei n. 8069, de 13/07/1990), vem reafirmar os princípios estabelecidos pela CF/1988, 
reconhecendo a criança como um ser de direito, portanto, como um ser merecedor de atenção integral (BRASIL, 1990). Caracteriza-se esta década e nas posteriores por transformações jurídico-institucionais, visíveis nos documentos mencionados e noutros, como: o Plano Nacional de Educação - PNE 2014-2024 (Lei n. 13.005, de 25/06/2014); o Fundo de Manutenção e Desenvolvimento da Educação Básica e de Valorização dos Profissionais da Educação FUNDEB (Lei n. 11.494, de 20/06/2007), e nesse contexto, o Programa Nacional de Reestruturação e Aquisição de Equipamentos para a Rede Escolar Pública de Educação Infantil - Proinfância. (BRASIL, 2007).

Apesar dos avanços, os desafios persistem no século XXI no sentido de fomentar a qualidade da Educação Infantil, destacando-se neste quadro, a busca de padrões de qualidade quanto à estrutura física adequada ao desenvolvimento de ações da educação infantil e das indispensáveis condições pedagógicas necessárias a esse fim.

Quanto ao primeiro aspecto, destacamos como importante o documento do MEC sobre os indicadores de qualidade na educação infantil, postos como fundamentais para a instituição de Educação Infantil no seu fazer cotidiano: planejamento institucional; multiplicidade de experiências e linguagens; interação, promoção da saúde; formação e condições de trabalho das professoras e demais funcionários; espaço, materiais e mobiliários (BRASIL, 2009).

Ainda, quanto à relevante questão em destaque, isto é, a qualidade da Educação Infantil, é oportuno ter em evidência a primeira meta do PNE 2014-2024 (BRASIL, 2014), que trata da universalização da Educação Infantil, ou seja, da expansão de vagas para pré-escolas no mínimo de $50 \%$ de oferta, prevista, àquela época, para até 2016.

Meta 1: universalizar, até 2016, a educação infantil na pré-escola para as crianças de 4 (quatro) a 5 (cinco) anos de idade e ampliar a oferta de educação infantil em creches, de forma a atender, no mínimo, 50\% (cinquenta por cento) das crianças de até 3 (três) anos até o final da vigência deste PNE. (BRASIL, 2014). 
Nessa perspectiva, cabe aos entes federados, particularmente aos municípios, levar a termo essa etapa da educação, fazendo-a acontecer. O ponto de partida está, por suposto, em concretizar os acordos e tratados assinados pelo país, implementar as reformas e cumprir as metas previstas, em seu total. Entretanto, tais dispositivos das políticas direcionadas para a educação infantil não são de fácil implementação, haja vista os complexos condicionantes sociais, políticos e econômicos que podem dificultar ou mesmo impedir a concretização de metas previstas. Ademais, as diferenças regionais são fatores de peso a sustar a implementação de políticas educacionais, principalmente se assentadas essas diferenças em desigualdades econômicas geradoras de elevados índices de pobreza.

Os desafios estão postos se se considerar a educação como um direito da criança e como dever do Estado em provê-lo e, para tanto, pautar esse cumprimento na inseparabilidade do cuidareducar, haja vista que a criança precisa "[...] ser educada e ensinada desde que nasce, considerando-se todas as dimensões do seu desenvolvimento: física, cognitiva, afetiva e social." (SOUSA, 2012, p. 210).

O CUIDAR E O EDUCAR CRIANÇAS PEQUENAS: relações com o espaço físico

A atenção com o espaço físico para o cuidar e educar crianças pequenas não é recente, tanto que a preocupação com o mobiliário escolar para esse atendimento já estava presente no Brasil desde o século XIX. Nesse século, apesar das precariedades marcantes a assinalar a educação, mormente a primária, alguns temas se mostram relevantes no ainda tímido cenário educacional, a exemplo das discussões sobre a necessidade de incorporar ao processo de escolarização setores sociais tidos como "inferiores", no caso negros, índios e mulheres. Faria Filho (2000) assinala a obrigatoriedade estabelecida por muitas leis provinciais para tornar obrigatória a frequência da população livre à escola. Este autor esclarece os limites da efetividade dessas leis, dado o escasso espaço de atuação do 
Estado, cuja presença nesse âmbito foi considerada, algumas vezes, perniciosa. Além disso, prossegue esclarecendo que à época "[...] nem a própria escola tinha um lugar social de destaque, cuja legitimidade fosse incontestável." (FARIA FILHO, 2000, p. 135-136).

Nesse contexto, uma escolarização no nível denominado de primeiras letras, ou seja, correspondente aos domínios elementares da leitura, da escrita e do cálculo, se concretizava em escolas que funcionavam em espaços os mais diversificados: igrejas, lojas maçônicas, prédios comerciais, dependências das câmaras municipais e, não raro, na própria residência dos mestres. Assim, simultaneamente às poucas escolas vinculadas ao poder estatal, instala-se, naquele nível, uma "rede de escolarização doméstica" de notável difusão (FARIA FILHO; VIDAL, 2000), porém sem os aparatos materiais e pedagógicos inerentes às atividades de ensino $\mathrm{e}$ aprendizagem.

A difusão desses "espaços escolares", embora com características domésticas, veio possibilitar às crianças de 0 a 6 anos conviver em ambientes externos à própria família, sendo um desses espaços as creches e os jardins de infância, ainda no final do século XIX. Como analisa Faria Filho (2000, p 145.), naquele século desenvolveu-se uma "[...] multiplicidade de modelos de escolarização, aos quais poder-se-ia somar, ainda, os dos colégios masculinos e femininos e o da preceptoria".

As creches têm maior desenvolvimento no século XX e na falta de legislação que as regulassem, foram consideradas como um lugar reservado para deixar as crianças em um período determinado, quando as famílias assim necessitassem; representavam, enfim, um lugar para a criança brincar e ser assistida com segurança por pessoas e até mesmo por qualquer pessoa com escolaridade em qualquer área de conhecimento, mais precisamente do sexo feminino.

A década de 70 representa um marco no desenvolvimento da educação infantil por se constituir como o período em que se expande a educação da criança calcada numa concepção de combate à pobreza e, simultaneamente, de melhoraria do desempenho do ensino fundamental. Trata-se de um modelo de educação de massa direcionado para países subdesenvolvidos, cujas bases conceituais se originam em orientações da Organização das Nações Unidas para a 
Educação, a Ciência e a Cultura (UNESCO) e do Fundo da Nações Unidas para a Infância (UNICEF), na perspectiva de uma educação compensatória. (SOUSA; BARBOSA, 2012).

Esse modelo de educação compensatória direcionado para crianças pequenas se coaduna, a partir de então, com a Doutrina de Segurança Nacional defendida pelos governos militares, haja vista o caráter ameaçador que a pobreza representava, na visão governamental, para manter íntegra a segurança do país. Com tais propósitos a política formulada pelo MEC, do final da década de 70 para o início da de 80, recorre a um personagem de peso - a Legião Brasileira de Assistência (LBA)- que no âmbito da educação infantil desenvolvia o Projeto de Creches de abrangência nacional.

O Projeto de Creches veio para atender necessidades da população de baixa renda e quanto à sua concretização enfatizamos, para o objetivo deste trabalho, aspectos relativos ao espaço físico em que foram instaladas. Também, de modo similar ao funcionamento das escolas de primeiras letras do final do século XIX para o início do século $X X$, as creches, no momento histórico em pauta, ou seja, no contexto de uma política de viés compensatório, poderiam ser instaladas em espaços os mais diversificados: salões de igrejas, centros sociais, associações de bairros, e outros.

Pela política do MEC, operacionalizada pela LBA, não eram exigidos espaços apropriados para o funcionamento das creches, tampouco uma estrutura física específica, portanto, muito menos mobiliário que desse suporte às atividades do cuidar e educar crianças pequenas. Os espaços acabavam por ser improvisados, recursos financeiros escassos e sem a exigência de qualificação específica dos profissionais que cuidavam das crianças. (CONCEIÇÃO, [2020]).

A década de 80 se sobressai pela ampliação do debate acadêmico e científico que põe em relevo o atendimento da criança em todo o país. Sousa e Barbosa (2012) atentam para a importância dessas discussões na medida em que contribuíram para a garantia dos direitos das crianças nos documentos oficiais, em especial a Constituição Federal de 1988, que definiu a integração das creches e pré-escolas ao sistema educacional brasileiro, como direito da criança e dever do Estado. 
Como tangenciado, na década de 90 a política do MEC para a educação infantil se volta para estabelecer metas com vistas à expansão com critérios de qualidade, afastando-se, assim, do modelo compensatório não formal. São encaminhamentos políticos articulados à concepção da criança como um ser de direito, concepção que ganha força com a promulgação do Estatuto da Criança e do Adolescente (ECA), em 1990, e com a Lei de Diretrizes e Bases da Educação Nacional - LDBN, em 1996, e legislações complementares, como referido (BRASIL, 1996).

Cumpre lembrar no rol das discussões nacionais e internacionais que então se intensificavam, focadas nos direitos das crianças e na qualidade dos serviços a elas direcionados, a elaboração em 1995 do documento "Critérios para um atendimento em creches que respeite os direitos fundamentais das crianças", que explicita critérios relativos ao cuidar de crianças de 0 a 6 anos de idade, bem como a definição de diretrizes e normas políticas e sistemas de financiamento de creches. Entre os critérios relativos às políticas e programas de creches, o documento destaca o compromisso com o bem-estar e o desenvolvimento da criança; reconhece que as crianças têm direito a um ambiente aconchegante, seguro e estimulante; têm direito à brincadeira, a uma alimentação saudável, à higiene e à saúde; põe em relevo que os projetos de construção e reforma das creches visam, sobretudo, ao bem-estar e desenvolvimento da criança, sendo os profissionais elemento chave para garantir a efetividade desses processos (CAMPOS; ROSEMBERG, 2009).

Todavia, as conquistas democráticas advindas desde a Constituição Federal de 1988 não ficaram imunes às orientações do Banco Mundial quanto aos direcionamentos da educação infantil no Brasil. Entretanto, por caminhos contraditórios, os avanços decorrentes de todo um aparato legal e de pressões sociais e políticas, encontram espaço no século XXI, por força de um contexto político com relativo grau de resistência aos imperativos de agências multilaterais, quando prosseguem transformações jurídicoinstitucionais afetas ao campo da educação escolar e, em particular, ao da educação infantil. O Programa Nacional de Reestruturação e Aquisição de Equipamentos para a Rede Escolar Pública de Educação Infantil (Proinfância) se insere neste contexto. 
PROINFÂNCIA: resposta aos avanços na construção da educação com qualidade para crianças pequenas?

O Programa Nacional de Reestruturação e Aquisição de Equipamentos para a Rede Escolar Pública de Educação Infantil (Proinfância), instituído pela Resolução n 6, de 24 de abril de 2007, emerge num conjunto de políticas focadas na melhoria da qualidade da educação básica cujos desdobramentos incidem, entre outros aspectos, na promoção da Educação Infantil, no incremento da inclusão educacional de pessoas com deficiência, no desenvolvimento de programas de formação inicial e continuada de professores, na promoção da valorização dos profissionais da educação (BRASIL, 2007).

Este Programa nasce, em suma, como uma das ações do Plano de Desenvolvimento da Educação (PDE) do MEC, com o propósito de garantir 0 acesso de crianças a creches e escolas e a promover a melhoria da infraestrutura física da rede de Educação Infantil. O solo em que é instituído traz a marca de um espaço social impregnado por orientações políticas afastadas do viés compensatório que marcou o atendimento a crianças e suas famílias até as décadas finais do século XX. Sobre isso, Albuquerque (2017) analisa a ocorrência, no governo Lula da Silva (século XXI), do arrefecimento, ainda que relativo, da estreita parceria estabelecida na década de 1990 entre o governo brasileiro e organismos internacionais, o que veio alargar o espaço para o estabelecimento de políticas de desenvolvimento com inclusão social e de promoção da educação com qualidade.

Assim, com o intuito de viabilizar as metas e diretrizes estabelecidas pelo PDE para a consecuução de ações efetivas de intervenção visando a transformação da realidade das escolas públicas de educação básica do país, o MEC cria, em 2007, o Plano de Ações Articuladas (PAR), concebido como um instrumento jurídico que inclui em seu raio de ação a infraestrutura física das escolas e recursos pedagógicos e a formação de professores e dos profissionais envolvidos com a escola.

Originado em tal contexto jurídico-político, o Proinfância tem a sua atuação distribuída em dois eixos: 
1) Construção de creches e pré-escolas, por meio da assistência técnica e financeira do Fundo Nacional de Desenvolvimento da Educação (FNDE), com projetos padronizados fornecidos pelo FNDE ou projetos próprios elaborados pelos proponentes (BRASIL, 2007);

2) Aquisição de mobiliário e equipamentos adequados ao funcionamento da rede física escolar da educação infantil, tais como mesas, cadeiras, berços, geladeiras, fogões e bebedouros (BRASIL, 2007);

Trata-se, portanto, de um modelo padronizado para grandes centros (capitais) e pequenos municípios, cabendo aos proponentes optarem pela construção ou pela aquisição de equipamentos e mobiliários, ou ambos.

Cabe salientar que este Programa indica estar alinhado às orientações políticas que se vinham delineando desde a Constituição Federal de 1988, na medida em que este instrumento jurídico reconhece $o$ atendimento em creches e pré-escolas como um direito social das crianças, ou seja, o reconhecimento da Educação Infantil como um dever do Estado, calcada em padrões de qualidade. São alinhamentos a ganhar mais consistência a partir da primeira década do século XXI, expressos em aparatos jurídico-institucionais alicerçados na concepção da criança como um ser de direitos.

$\mathrm{Na}$ esteira desses alinhamentos situa-se o Plano Nacional de Educação, em vigor, PNE -2014/2024, que prescreve entre as estratégias referentes à meta de universalizar a educação infantil (Meta 1) - a de:

1.5- Manter e ampliar, em regime de colaboração e respeitadas as normas de acessibilidade, programa nacional de construção e reestruturação de escolas, bem como de aquisição de equipamentos, visando à expansão e à melhoria da rede física de escolas públicas de educação infantil (BRASIL, 2014).

No contexto das políticas em empreendimento, a instituição do Proinfância veio participar como uma resposta às reivindicações 
de mães/mulheres para o desenvolvimento de uma educação de qualidade que atendesse às condições adequadas de trabalho nas escolas da rede pública e, neste caso específico, em pré-escolas e creches.

Para empreendimentos de tal envergadura, centrados na garantia do direito à educação básica com qualidade, impõe-se a necessária articulação entre os entes federados; em termos práticos, pela adesão dos governos por meio da assinatura do Plano de Metas Compromisso Todos pela Educação. Compromisso que, por sua vez, exige para sua execução a adoção de um plano de ação - Plano de Ações Articuladas (PAR).

Como estamos a acentuar, o aprimoramento da instituição de educação infantil indica reivindicar uma estrutura física padronizada, ou seja, um ambiente coletivo com espaços adequados e conforto para atender as crianças conforme as normas vigentes no país; o Proinfância busca atender essa identidade que requer, portanto, um mobiliário com requisitos considerados imprescindíveis ao atendimento do bem-estar físico e psicológico das crianças e do trabalho dos (as) professores (as) e dos demais profissionais, em consonância com uma educação infantil de qualidade. Tais especificações, condicionadas à faixa etária da criança traduzem-se em termos de:

Qualidade técnica: em que se considera a eficiência com que o produto executa sua função, a facilidade de manutenção e limpeza entre outros fatores;

Qualidade ergonômica: que inclui a facilidade de manuseio, a adaptação antropométrica, o fornecimento claro de informações, as compatibilidades de movimentos e demais itens de conforto e segurança;

Qualidade estética: que envolve a combinação de formas, cores, uso de materiais, textura para que os produtos sejam visivelmente agradáveis, entre outros. (BRASIL, 2007, p. 2).

É importante destacar que esse Programa nasceu da reunião de entidades envolvidas nas discussões em prol da qualidade da 
estrutura de creches e pré-escolas com o intuito de conferir-lhes uma identidade e o ponto de partida foi estabelecida pelos Parâmetros Básicos de Infraestrutura para Instituições de Educação Infantil, em 2006. Na elaboração desse documento foram consultados, além de educadores, técnicos da área da construção civil, como arquitetos e engenheiros, entre outros profissionais, conforme se vê a seguir:

A construção coletiva das políticas públicas para a educação foi elaborada em parceria com educadores, arquitetos e engenheiros envolvidos em planejar, refletir e construir/ reformar os espaços destinados à educação das crianças de 0 a 6 anos. Com o objetivo de propiciar o cumprimento do preceito constitucional de descentralização administrativa, bem como a participação dos diversos atores da sociedade envolvidos com a educação infantil na formulação das políticas públicas voltadas para as crianças de 0 a 6 anos, foram realizados, em parceria com as secretarias municipais de educação e com a União Nacional dos Dirigentes Municipais de Educação - UNDIME, oito seminários regionais para a discussão do documento preliminar. Os municípios que sediaram os seminários foram: Belo Horizonte, Natal, Belém, Recife, São Paulo, Porto Alegre, Goiânia e Manaus. (BRASIL, 2006, p. 3)

Igualmente importantes, quanto os cuidados referentes à estrutura física para o desenvolvimento com qualidade da educação de crianças, são as políticas públicas focadas na formação inicial e continuada dos (as) professores (as) que atuam nessa etapa da Educação Básica. Assim, cabe aos sistemas de ensino medidas que promovam a "habilitação exigida pela legislação para os profissionais que ainda não a possuem; promovam a formação continuada dos professores e de outros profissionais que atuam nas instituições de Educação Infantil", bem como aos auxiliares de creches e cuidadoras (BRASIL, 2008).

Levados em consideração esses aspectos, entendemos que o trabalho com crianças, principalmente em creches, vai além do cuidado em assisti-las ou acompanhá-las em algumas horas; é um 
trabalho que exige desse profissional conhecimento científico e atualizado. É nessa direção que os Parâmetros Nacionais de Qualidade da Educação Infantil destacam o professor como peçachave na promoção da qualidade da Educação Infantil, mostrando a necessidade de que sejam propiciadas:

$$
\begin{aligned}
& \text { [...] condiçães para sua valorização e } \\
& \text { desenvolvimento profissional: salário; carreira; } \\
& \text { jornada; participação efetiva na elaboração e } \\
& \text { condução dos projetos pedagógicos da instituição; } \\
& \text { formação inicial e continuada, com foco no } \\
& \text { desenvolvimento infantil, garantindo espaço para a } \\
& \text { pluralidade e para que Professores ampliem seu } \\
& \text { saber e seu saber fazer com as crianças; formação } \\
& \text { permanente. (BRASIL, 2006, p. 33) }
\end{aligned}
$$

No âmbito das políticas educacionais empreendidas quando da criação do Proinfância situam-se as direcionadas para a formação de profissionais do magistério da Educação Básica; entre estas o Programa de Formação Inicial para Professores em Exercício na Educação Infantil - Proinfantil - criado pelo MEC, em 2005, cujos objetivos consistem em:

\begin{abstract}
Habilitar para o magistério, em nível médio, os professores que exercem atividades docentes na educação infantil; elevar o nível de conhecimento e aprimorar a prática pedagógica dos docentes em exercício; valorizar o magistério, oferecendo condições de crescimento profissional e pessoal ao professor; contribuir para a qualidade social da educação das crianças de 0 a 6 anos, nas instituições de educação infantil. (BRASIL, 2005, p. 9)
\end{abstract}

Este Programa veio ao encontro das necessidades de qualificação em nível médio na modalidade Normal de professores (as) em atuação na educação infantil, que em regiões como o Nordeste eram marcantes. No estado do Maranhão havia, à época da implantação do Programa, notável contingente de professores (as) dessa etapa da Educação Básica com escolarização em nível fundamental apenas, ou em nível médio, mas sem formação pedagógica exigida por lei. Nesse estado, o Proinfantil atendeu a 625 
e a 506 professores (as) nas duas últimas edições, em 2007 e em 2009, respectivamente. (NASCIMENTO; BONFIM, 2012).

Desde as décadas finais do século XX a infância e a criança têm sido alvo de maior atenção nas políticas públicas o que se coloca como um desafio às instituições que delas cuidam e educam em ofertar uma educação de qualidade. Qualidade que é construída, o que requer "um professor devidamente formado", como analisa Sousa (2012, p.207-208); um professor que orientado pela qualidade seja capaz de:

Desenvolver um trabalho docente sistematizado,
caracterizado pela sua intencionalidade educativa,
que, desde seu planejamento, considere a
historicidade, o contexto sociocultural, as
características, necessidades, ritmos, e as diferentes
linguagens de cada criança e do conjunto delas.

Os aspectos aqui enfocados, importantes para conferir qualidade à educação infantil: infraestrutura física (prédio, mobiliário escolar/equipamentos) e professores devidamente formados, foram analisados em uma creche municipal padrão Proinfância, inaugurada em dezembro de 2018, localizada em um conjunto de casas populares para pessoas de baixa renda, no município de São José de Ribamar, no estado do Maranhão.

\section{O PROINFÂNCIA EM SÃO JOSÉ DE RIBAMAR}

A adesão do município de São José de Ribamar ao Proinfância deu-se por meio de alguns passos, necessários à sua implementação, a começar pela adesão ao Plano de Metas Compromisso Todos pela Educação, com posterior elaboração de um plano integrado ao Plano de Ações Articuladas (PAR). Neste constava a demanda por vagas evidenciando a necessidade de que fossem construídas creches a partir de reivindicações de moradores de um conjunto popular desse município, constituído por pessoas de baixa renda. Tais reivindicações se expressaram quando da entrega do conjunto residencial, ocasião em que o prefeito realizou uma reunião com uma comissão de moradores sugerindo que fosse escolhido o 
primeiro benefício entre os que a prefeitura poderia atender: um posto de saúde, um posto policial, uma escola de ensino fundamental ou uma creche, tendo sido a creche escolhida como a primeira e maior ação de política pública que caberia à prefeitura atender naquele momento.

A demanda por educação infantil é um fenômeno em expansão, consequência de processos acelerados de urbanização associados a uma vigorosa participação da mulher no mercado de trabalho, o que gera profundas modificações na organização e na estrutura da família (CARMO; BISSOLI, 2012; SOUSA, 2012). Assim, em resposta àquelas reivindicações, a prefeitura do município mobilizouse para a construção de cinco creches e aquisição de mobiliário escolar, dentro daquele padrão. Por pressão de demandas das famílias, a creche, lócus deste estudo, construída para acolher a 240 crianças em dois turnos, teve, por determinação judicial, o seu atendimento expandido para 270 crianças daquele bairro e adjacências. $^{3}$

As 11 professoras participantes da pesquisa desenvolvem uma percepção positiva sobre a qualidade da estrutura física da creche exemplificada como ambiente espaçoso, novo, salas amplas, pátio coberto para as brincadeiras, brinquedoteca, banheiros adequados para o cuidar de crianças de 0 a 5 anos, entre outros requisitos.

Entretanto, destacam inapropriações em relação a algumas instalações devido às condições específicas de uma região quente, como aquela onde a creche está situada, que se caracteriza por um

3 NR1 - A creche, construída no conjunto habitacional Nova Terra, é do tipo B, com 8 (oito) salas de atividades, correspondendo ao atendimento de até 240 crianças em dois turnos, ou 120 crianças em período integral. Todavia, atendia à época da pesquisa a 275 crianças, sendo o excedente matriculado por determinação judicial. Quanto aos profissionais que lá atuam 11 são professoras formadas em Pedagogia, todas com experiência em educação infantil; 1 diretora e 1 coordenadora, ambas com formação em nível superior e com especialização em Gestão Escolar; 1 pedagoga em atuação na sala de Atendimento Educacional Especializado (AEE) e outros profissionais também ligados ao cuidar/educar as crianças em funções administrativas (secretária, cuidadoras, auxiliares de creche, operacionais de serviços diversos (OSD), merendeiras, guarda municipal). 
clima elevado. Uma delas refere-se ao espaço construído para funcionar como um teatrinho, como relata a Diretora da creche:

Outra coisa é o espaço no momento da peça teatral: o teatrinho. Bom, sei que para uma escola do sul e sudeste, você tem lá outra temperatura; lá você pega 17, 18 e 20 graus, lá funciona. Prá gente fica inviável à tarde pegar as crianças e levar prá lá porque é muito quente. De manhã ainda dá uma sombrinha até umas $9 \mathrm{~h} 30 \mathrm{~m}$, depois já é o solzão; então, no caso, são altas temperaturas. É complicado; então, não tem muita utilidade. (SILVA, 2020, f. 97)

Todavia esse é, sem dúvida, um espaço muito importante para a educação de crianças daquele município que é reconhecido pela brincadeira do Bumba-Meu-Boi; brincadeira presente na vida dessas crianças, pois muitas são filhas e netas de brincantes dessa cultura e, como tal, gostam de representar, cantar e ouvir.

Entretanto, aspectos de maior realce quanto à qualidade da educação de crianças pequenas recaem sobre questões para além das condições materiais/infraestruturais e inovadoras para o contexto educacional daquele município.

Em coerência ao horizonte das políticas de inclusão, uma das dimensões do reconhecimento da criança como um ser de direitos, a creche em estudo recebe crianças com deficiência. Entretanto, segundo relato das Professoras:

Faltou a famosa educação inclusiva, faz falta em todos os âmbitos, na verdade não há uma inclusão, há uma adaptação e inserção dessas crianças com deficiências/transtornos dentro da sala de aula. Entre o que você estuda na universidade e o que você vê na prática ela é bem mais complicada de ter aplicabilidade, a efetiva aplicabilidade. (SILVA, 2020, f. 93).

O relato acima refere-se ao fundamental para a realização do trabalho pedagógico em qualquer nível e modalidade de ensino formação inicial e formação continuada dos professores - que, se distanciadas da realidade a lhes exigir concretude, ou seja, se 
sedimentadas num terreno polarizador das exigências de articulação teórico-prática, podem redundar em sérios entraves aos objetivos educacionais a que se propõem. Podem impactar negativamente $o$ trabalho docente precarizando-o, conduzindo, enfim, ao adoecimento dos (as) professores (as), conforme relatam:

$\mathrm{Na}$ verdade, você chega à conclusão de que você tem até um desgaste psicológico dessa devida inclusão, dizer assim ah! eu estudei aquela teoria, não é que ela não seja importante, ela é de suma importância porque ela dá subsídio a todas as ações mas a gente verifica que essa efetividade de inclusão ela é muito falha ainda e tem lacunas enormes que tão cedo não vão ser sanadas do jeito que esses projetos são feitos voltados nessa área. (SILVA, 2020, f. 93)

Cumpre destacar que é consenso entre as professoras a necessidade de aperfeiçoamento e aprofundamento dos conhecimentos auferidos na formação inicial, pois estão diante de um novo desafio: a inclusão de alunos com deficiência em salas comuns. Desafio para o qual a licenciatura, embora reconhecida como efetiva formação, deixa em aberto algumas lacunas, percebidas, principalmente, em termos de um distanciamento da teoria estudada em relação ao posterior exercício profissional.

Cumpre também destacar que este aspecto da inclusão, aqui tangenciado, é tão somente um entre outros que evidenciam a necessidade do planejamento de ações, pelas instâncias gestoras, na promoção de formação continuada para as professoras, dado que esta

[...] deve capacitá-los para conhecer melhor o que hoje se sabe das possibilidades de trabalho pedagógico de promoção do desenvolvimento de todas as crianças com necessidades educacionais especiais, bem como para auxiliar essas crianças na construção de conhecimentos cada vez mais ampliados e significativos acerca do mundo e de si mesmas. (OLIVEIRA, 2008, p. 246). 
O que queremos ressaltar sobre a qualidade da educação de crianças pequenas, em creches e pré-escolas, envolve, sem dúvida, um ambiente físico como um espaço organizado com mobiliário e equipamentos, suportes importantes para as práticas sociais ali desenvolvidas. Mas envolve, sobretudo, o componente humano, crianças em desenvolvimento e, neste caso particular, professores (as) qualificados (as) e com disponibilidade para contínuo aperfeiçoamento, dado que "[...] todo contexto ambiental é um sistema de inter-relações dos vários componentes físicos e humanos que dele participam." (OLIVEIRA, 2008, p. 192).

\section{CONSIDERAÇÕES FINAIS}

Creches e pré-escolas são um ambiente interacional no qual convivem seres humanos mediados por suportes físicos, representados desde equipamentos e mobiliários até escolas construídas sob um padrão pré-definido, como o Proinfância.

Dos idos do século XIX até os dias de hoje, verificam-se mudanças substantivas nos artefatos físicos utilizados como meios auxiliares no cuidar e educar crianças pequenas, bem como nos espaços e ambientes em que se materializam essas ações educativas. Como ambiente interacional, as creches e pré-escolas têm sido organizadas ao longo dos anos sob determinadas concepções (de criança, de mundo, de educação), variáveis no tempo e no espaço geográfico em que se situam.

Com a perspectiva de estender educação à população pobre, tida como desprovida de bens culturais segundo parâmetros importados de outros países, dissemina-se no Brasil, ao tempo do regime militar, um modelo de educação de caráter compensatório e preventivo (educação de massa). Este modelo de educação destinado à criança pequena, pautado em tal concepção, com fortes vínculos com a assistência social, trouxe consigo repercussões sobre o aparato espacial (físico e social) em que se desenvolvia: instalações físicas improvisadas, ausência da exigência de qualificação legal ao componente humano responsável por suprir as "carências" infantis, além de evidenciar a ausência quase total do Estado neste empreendimento. 
Os avanços na bandeira de redemocratização do país, já na década de 1980, incluem mudanças significativas no espectro político, social e cultural com implicações na educação infantil, não no sentido de reinventá-la, mas de ressignificá-la em direção à inseparabilidade do cuidar com o educar. Marca, assim, gradativo distanciamento de concepções de criança que a têm imersa numa rede assistencialista e compensatória das "carências" que a acometem.

Daí em diante todo um aparato legal que se vai forjando sob fortes pressões de entidades da sociedade civil e de movimentos organizados, dá um suporte essencial (material e humano) à educação das crianças pequenas, agora concebidas como seres de direito (embora não universais na prática, é prudente reconhecer).

O Proinfância emerge nesse contexto e se propõe como um Programa a atender a várias demandas, tanto as que se referem ao bem-estar das crianças quanto às relacionadas à qualidade profissional dos que atuam na Educação Básica, aspectos que, na verdade, devem ser indissociáveis no escopo de uma educação de qualidade.

Os dois eventos na creche em São José de Ribamar, há pouco abordados, expõem, de um lado, inadequações na construção do espaço físico comprometedoras do desenvolvimento das atividades exploratórias e criativas das crianças; de outro, o comprometimento de contextos de aprendizagem de crianças com deficiência, embora estivessem presentes aportes ambientais e pedagógicos, estes referentes à formação dos (as) professores (as). Em ambos os eventos, o espaço físico e social da sua ocorrência foi o mesmo.

Por fim, sem a intenção de concluir, queremos registrar que a retomada dos elementos que envolvem a educação infantil permitenos inferir, com base no estudo realizado, que os suportes infraestuturais necessários a uma educação de qualidade ganham sentido se estreitamente conjugadas com outras condições tão fundamentais quanto aquelas. Condições pedagógicas, não necessariamente restritas a materiais de apoio para o exercício das funções dos que lidam com crianças pequenas, mas que incidem necessariamente na formação desses profissionais, mormente dos 
(as) professores (as) e demais profissionais envolvidos na educação de crianças.

\section{REFERÊNCIAS}

ALBUQUERQUE, Severino Vilar de. A política educacional do Plano de Desenvolvimento da Educação (PDE): outra qualidade para a Educação Básica?. Pesquisa em Foco, São Luís, v. 22. n. 1, jan./jun., p. 178-199, 2017. Disponível em:

https://45.71.6.41/index.php/PESQUISA_EM_FOCO/article/view/1402 /1094. Acesso em: 19 ago. 2020.

BRASIL. Lei n. 8.069, de 13 de junho de 1990. Dispõe sobre o Estatuto da Criança e do Adolescente e dá outras providências. Diário Oficial da União: Brasília, DF, 6 jul. 1990 e retificado em 27 set. 1990. Disponível em:

http://www.planalto.gov.br/ccivil_03/leis//8069.htm. Acesso em: 1 jan. 2020.

BRASIL. Lei no 11.494, de 20 de junho de 2007. Regulamenta o Fundo de Manutenção e Desenvolvimento da Educação Básica e de Valorização dos Profissionais da Educação - FUNDEB, de que trata o art. 60 do Ato das Disposições Constitucionais Transitórias; altera a Lei n o 10.195, de 14 de fevereiro de 2001; revoga dispositivos das Leis nos 9.424, de 24 de dezembro de 1996, 10.880, de 9 de junho de 2004, e 10.845, de 5 de março de 2004; e dá outras providências. Diário Oficial da União: Brasília, DF, 21 jun. 2007, retificado 22 jun. 2007. Disponível em: http://www.planalto.gov.br/ccivil_03/_ato20072010/2007/lei/l11494.htm. Acesso em: 19 ago. 2020.

BRASIL. Ministério da Educação e do Desporto. Lei n. 9.394, de 20 de dezembro de 1996. Estabelece as Diretrizes e Bases da Educação Nacional. Diário Oficial da União: Brasília, DF, 23 dez. 1996. Disponível em:

http://www.planalto.gov.br/ccivil_03/leis/19394.htm. Acesso em: 1 jan. 2020.

BRASIL. Ministério da Educação. Diretrizes gerais. Proinfantil: Programa de Formação Inicial para Professores em Exercício na 
Educação Infantil. Brasília, DF: MEC/SEB, 2005. Disponível em: http://portal.mec.gov.br/seb/arquivos/pdf/Educinf/diretrizes.pdf. Acesso em: 19 ago. 2020.

BRASIL. Ministério da Educação. Fundo Nacional de Desenvolvimento da Educação. Resolução n. 6, de 24 de abril de 2007. Institui o Programa Nacional de Reestruturação e Aquisição de Equipamentos para a Rede Escolar Pública de Educação Infantil (Proinfância). Brasília, DF: MEC, FUNDEB, 2007. Disponível em: http://portal.mec.gov.br/arquivos/pdf/resolucao_n6_240407_proinfa ncia_medida18.pdf.pdf. Acesso em: 19 ago. 2020.

BRASIL. Ministério da Educação. Indicadores da Qualidade na Educação Infantil. Brasília, DF: MEC/SEB, 2009. Disponível em: http://portal.mec.gov.br/dmdocuments/indic_qualit_educ_infantil.pd f. Acesso: 19 ago. 2020.

BRASIL. Ministério da Educação. Lei 13.005/2014. Aprova o Plano Nacional de Educação - PNE e dá outras providências. Brasília/DF: MEC, 2014. Disponível em: http://pne.mec.gov.br/18-planossubnacionais-de-educacao/543-plano-nacional-de-educacao-lei-n13-005-2014. Acesso em: 15 set. 2019.

BRASIL. Ministério da Educação. Secretaria de Educação Básica. Parâmetros Básicos de Infraestrutura para Instituições de Educação Infantil. Brasília, DF: MEC, SEB, 2006. Disponível em: http://portal.mec.gov.br/seb/arquivos/pdf/Educinf/eduinfparinfesten carte.pdf. Acesso em: 19 ago. 2020.

BRASIL. Ministério da Educação. Secretaria de Educação Básica.

Parâmetros nacionais de qualidade para a educação infantil. Brasília, DF: MEC, 2008, v. 2. Disponível em: http://portal.mec.gov.br/seb/arquivos/pdf/Educinf/eduinfparqualvol 2.pdf. Acesso em: 19 ago. 2020.

BRASIL. Constituição da República Federativa do Brasil de 1988. Brasília, DF: Presidência da República, 1998. Disponível em: http://www.planalto.gov.br/ccivil_03/constituicao/constituicao.htm. Acesso em: 1 jul. 2019. 
CAMPOS, Maria Malta; ROSEMBERG, Fulvia. Critérios para um Atendimento em Creches que respeite os Direitos Fundamentais das Crianças. 6. ed. Brasília, DF: MEC/SEB, 2009. 44p.

CARMO, Ana Claudia Paula do; BISSOLI, Michelle de Freitas. A formação de professores para Educação Infantil em Boa Vista: a política municipal e o papel da Universidade Federal de Roraima.

Revista Educação e Emancipação, São Luís/MA: EDUFMA, v. 5, n. 2, jul./dez., 2012, p. 9-33.

CONCEIÇÃO, C. M. C. Histórias de um passado não tão distante: políticas e práticas de educação infantil no interior do Brasil. [2020]. 13p. Disponível em:

http://sbhe.org.br/novo/congressos/cbhe7/pdf/04\%20HISTORIA\%20DA\%20EDUCACAO\%20DAS\%20CRIANCAS\%20JOVENS\%20E\%20ADULTOS\%20NO\%20BRASIL/HISTORIAS\%20D E\%20UM\%20PASSADO\%20NAO\%20TAO\%20DISTANTE.pdf. Acesso em: 19 ago. 2020.

FARIA FILHO, Luciano Mendes de. Instrução Elementar no Século XIX. In: LOPES, Eliane Marta Teixeira; FARIA FILHO, Luciano Mendes de; VEIGA, Cynthia Greive (org.). 500 Anos de Educação no Brasil. Belo Horizonte: Autêntica Editora, 2000. p.135-150.

FARIA FILHO, Luciano Mendes de; VIDAL, Diana Gonçalves. Os tempos e os espaços escolares no processo de institucionalização da escola primária no Brasil. Revista Brasileira de Educação, Campinas/SP: Autores Associados, n.14, maio/ago., 2000. p. 19-34.

LEITE FILHO, A. G; NUNES, M. F. Direitos da criança de educação infantil: reflexões sobre a história e a política. In: KRAMER, S.; NUNES, M. F.; CARVALHO, M. C. (org.). Educação Infantil: formação e responsabilidades. 1.ed. [São Paulo]: Papirus, [2013]. cap. 3.

NASCIMENTO, IIma Vieira do; BONFIM, Maria Nubia Barbosa. O proinfantil no quadro de uma política de formação de professores. In: NASCIMENTO, Ilma Vieira do;

OLIVEIRA, Zilma Ramos de. Educação Infantil: fundamentos e métodos. São Paulo: Cortez, 2008. p. 192-246. (Coleção docência em formação) 
SILVA, Nelcir Francisca da. Repercussões da formação de professores (as) no contexto de uma creche do Programa Proinfância no município de São José de Ribamar. 2020. 136 f. Dissertação (Mestrado em Educação) - Universidade Federal do Maranhão, Programa de Pós-Graduação em Educação, São Luís, 2020.

SOUSA, Maria de Fatima Guerra de. Contextos de Aprendizagem e Trabalho Docente: desafios da qualidade na educação infantil. In: NASCIMENTO, Ilma Vieira do; TEÓFILO, Maria da Penha (org.). Proinfantil e sua interface com a formação continuada de professores: recortes de uma experiência no Maranhão. São Luís: EDUFMA, 2012. p. 207-228.

SOUSA, Rosiris Pereira de; BARBOSA, Ivone Garcia. Educação Infantil: políticas públicas e práticas educativas na pré-escola de escolas municipais de ensino fundamental em Goiânia. 2012. 207 f. Dissertação (Mestrado em Educação) - Universidade Federal de Goiás, Programa de Pós-Graduação em Educação, Goiânia, 2012.

SOUZA, C. A. Entrelinhas: infantil 4. Manual do Professor. 2. ed. Curitiba: Sistema Educacional Família e Escola, 2011.

TEÓFILO, Maria da Penha (org.). Proinfantil e sua interface com a formação continuada de professores: recortes de uma experiência no Maranhão. São Luís: EDUFMA, 2012. p. 25-45.

Submetido em: Setembro/ 2020.

Aceito em: Outubro/ 2020. 